\title{
Desmatamento e Crescimento Econômico no Brasil: uma análise da Curva de Kuznets Ambiental para a Amazônia Legal
}

\author{
Rejane Corrêa de Oliveira ${ }^{1}$ \\ Eduardo Almeida ${ }^{2}$ \\ Ricardo da Silva Freguglia ${ }^{3}$ \\ Ricardo Candéa Sá Barreto ${ }^{4,5}$
}

Resumo: Nos últimos anos, tem sido crescente a preocupação de que o crescimento econômico possa causar o desmatamento na região amazônica. Este trabalho tem por objetivo estudar a relação entre crescimento da renda e desmatamento sob a hipótese da Curva de Kuznets Ambiental (Environmental Kuznets Curve - EKC), considerando-se os municípios da Amazônia Legal, no período de 2001 a 2006. Um modelo econométrico de dados em painel com dependência espacial foi estimado. Variáveis explicativas adicionais relatadas na literatura como importantes condicionantes do desmatamento (atividades agropecuárias, densidade populacional, entre outras) foram incluídas. A especificação que melhor se ajusta aos dados é a que inclui um termo de erro espacial e transbordamentos espaciais das variáveis explicativas. O formato encontrado para a relação entre desmatamento e crescimento não é o " $U$ " invertido tradicional, mas um " $\mathrm{N}$ " invertido.

1 Mestre em Economia Aplicada pela Universidade Federal de Juiz de Fora. E-mail: rejane.co@hotmail.com

2 Professor Adjunto da Faculdade de Economia da UFJF, pesquisador do CNPq e pesquisador PPM da Fapemig. E-mail: eduardo.almeida@ufjf.edu.br

3 Professor da Faculdade de Economia da UFJF. E-mail: ricardo.freguglia@ufjf.edu.br

4 Gestor de Ensino e Pesquisa da Fundação João Pinheiro e doutor em Economia Aplicada pela Universidade Federal de Viçosa. E-mail: ricardocandea@yahoo.com.br

5 Os autores agradecem os valiosos comentários feitos pelos pareceristas anônimos. Eduardo Almeida agradece o suporte financeiro do CNPq e da Fapemig para a elaboração deste artigo. 
710 - Desmatamento e Crescimento Econômico no Brasil:

uma análise da Curva de Kuznets Ambiental para a Amazônia Legal

Palavras-chave: Amazônia, Desmatamento, Curva de Kuznets Ambiental, Econometria espacial.

\begin{abstract}
Over the last years,concerns about the possibility that the economic growth may cause deforestation in the Amazon region have been increasing. This work is aimed at studying the relation between income and deforestation by the hypothesis of Environmental Kuznets Curve (EKC) approach at municipal level in the period from2001-2006. A panel data model with spatial dependence was estimated. Some other variables mentioned in the literature as important causes of deforestation (cattle and agricultural activities, population density and others) were included. The best model specified is the one that includes a spatial error term and spatial spillovers. The relation founded is not the traditional inverted " $U$ " shaped, but an inverted " $N$ " shaped relation.
\end{abstract}

Key-words: Amazon, Deforestation, Environmental Kuznets Curve, Spatial econometrics.

Classificação JEL: C21, C23, Q27 e Q56.

\title{
1. Introdução
}

O desmatamento das florestas tropicais se destaca como um elemento importante na questão das mudanças climáticas. No Brasil, o desmatamento provocado por focos de calor torna o país um grande emissor mundial de dióxido de carbono $\left(\mathrm{CO}_{2}\right)$, um dos gases causadores do efeito estufa. Há a preocupação de que, com o avanço do desenvolvimento, a pressão sobre as florestas tropicais aumente. O debate sobre crescimento econômico e degradação ambiental encontra na hipótese da Curva de Kuznets Ambiental (Environmental Kuznets Curve - EKC) uma expectativa de resposta.

A hipótese da EKC descreve uma relação de degradação ambiental crescente em regiões em desenvolvimento, com renda per capita baixa, porém, ao alcançar patamares tecnológicos superiores, aliados a mudanças na estrutura produtiva e políticas de proteção ambiental, haveria menor pressão ambiental e os indicadores de degradação ambiental poderiam apresentar queda para níveis de renda mais elevados, caracterizando uma curva com formato de " $U$ " invertido (STERN, 2004). Contudo, esta relação não é clara teoricamente (CHIMELI, 2007) e, do ponto de vista empírico, os resultados são contraditórios, dependendo do tipo de indicador de qualidade ambiental e variáveis empregadas. Alguns trabalhos confirmam a EKC, enquanto outros criticam a alta sensibilidade dos resultados às formas funcionais e especificações dos modelos (DE BRUYN et al., 1998; STERN, 2004). 
No Brasil, a grande preocupação atual da transformação da Amazônia ${ }^{6}$ reside sobre o processo de desmatamento, com isso, boa parte dos estudos sobre desmatamento de florestas tropicais centra-se nesta região, pela ameaça que representa sobre o acervo de biodiversidade e sobre a prestação de serviços ambientais para a manutenção das condições climáticas globais. Até 2007, cerca de $732 \mathrm{mil} \mathrm{km}{ }^{2}$ foram desmatados, o que corresponde a quase $15 \%$ da área total da região. Até 1980, o desmatamento na região alcançava cerca de 300 mil km², o equivalente a $6 \%$ da área total (BRASIL, 2008).

Com base no diagnóstico que consta no relatório "Plano Amazônia Sustentável" (BRASIL, 2008), a região caracteriza-se atualmente por uma economia cujos setores mais importantes são: agropecuário, florestal, mineral, industrial e atividades urbanas, entre as quais a administração pública tem importante peso. O relatório caracteriza a região da Amazônia brasileira como uma região heterogênea em vários aspectos. A relação do desmatamento com o crescimento econômico, portanto, torna-se uma questão de interessante complexidade.

A proposta deste trabalho é investigar a existência da relação causal entre degradação ambiental e crescimento econômico, preconizada pela hipótese da Curva de Kuznets Ambiental (Environmental Kuznets Curve - EKC), na região da Amazônia Legal, considerando seu indicador de degradação ambiental mais relevante, o desmatamento. Portanto, busca-se saber se existe uma relação na forma de " $U$ " invertido entre um índice de degradação ambiental (área desmatada anual) e o crescimento econômico (medido pelo PIB per capita) para todos os municípios da região mapeados pelo sistema Prodes (Inpe), durante o período de 2001 a 2006, utilizando um modelo para dados em painel com dependência espacial. Além da variável relativa à renda, foram adicionadas variáveis explicativas adicionais consideradas relevantes pela literatura, tais como: rebanho bovino, culturas agrícolas como soja e cana-de-açúcar, extração vegetal e silvicultura, densidade populacional, crédito rural e área de floresta preexistente.

Este artigo está organizado da seguinte forma: a seção 2 apresenta uma revisão de trabalhos anteriores acerca da EKC e o desmatamento de florestas tropicais, em especial a Amazônia brasileira, e outros condicionantes recentes do desmatamento desta região, com ênfase nos aspectos espaciais. A seção 3 apresenta as variáveis e métodos utilizados nas estimações dos modelos econométricos. A seção 4 apresenta os resultados e os discute. A última seção conclui, destacando os principais resultados e a contribuição de se considerar

6 A região da Amazônia Legal abrange os estados do Acre, Amapá, Amazonas, Mato Grosso, Rondônia, Roraima, Tocantins, Pará e parte do Maranhão (porção a oeste do Meridiano $44^{\circ}$ ), estendendo-se por 5,2 milhões de $\mathrm{km}^{2}$, o equivalente a $61 \%$ do território nacional (SUDAM, 2009). 
Desmatamento e Crescimento Econômico no Brasil:

uma análise da Curva de Kuznets Ambiental para a Amazônia Legal

os efeitos espaciais para a compreensão do processo de desmatamento e sua relação com o crescimento econômico da região amazônica.

\section{Revisão da literatura}

A hipótese da Curva de Kuznets Ambiental tem sido amplamente testada para diversos indicadores de degradação ambiental, em diferentes contextos temporais e espaciais. Além de ser aplicado a emissões de poluentes, o indicador de degradação ambiental considerado pela EKC pode também contemplar o desmatamento. A abrangência geográfica para a qual a EKC é investigada também é bastante diversa: análises multipaíses, nacionais, regionais e microrregionais podem ser encontradas nos trabalhos empíricos. Boas revisões podem ser encontradas em Stern (2004) e Carvalho (2008).

Para a degradação ambiental relacionada ao desmatamento de florestas, várias interpretações para a EKC são apresentadas na literatura. Battharai e Hammig (2001) explicam que, em geral, os países de baixa renda desmatam sem reposição, e à medida que a renda aumenta, o investimento em reflorestamento para reposição da madeira extraída ou para a produção de produtos florestais compensa a área desmatada. Além disso, a estrutura da economia e os padrões de demanda de energia mudam à medida que a renda cresce (por exemplo, a lenha consumida como combustível é substituída por carvão mineral e derivados de petróleo), reduzindo a pressão sobre as florestas. Lopez (1994, apud CULAS, 2007), desenvolveu um modelo teórico em que os efeitos de estoque dos recursos florestais (biomassa) na produção agrícola são internalizados, e então, o crescimento econômico resultaria em menor desmatamento.

Essa internalização poderia ser induzida por políticas governamentais ou arranjos contratuais entre produtores. Culas (2007) cita outras forças indutoras para uma trajetória típica da EKC, como a atratividade de empregos não rurais para manter as pessoas fora da floresta, um maior valor atribuído às florestas intocadas, e a capacidade dos governos de reforçar a proteção das florestas por meio de fatores institucionais. Esses fatores influenciariam a altura e a convexidade da EKC, acelerando o caminho para o desenvolvimento sustentável.

Dado o crescente interesse em modelos sobre o desmatamento, Kaimowitz e Angelsen (1998) realizaram uma abrangente revisão dos trabalhos publicados sobre o tema até 1998. Segundo Barbier e Burgess (2002), os trabalhos que buscam identificar as causas do desmatamento em florestas tropicais podem ser categorizados da seguinte forma: aqueles que, em nível macroeconômico, testam a hipótese da Curva de Kuznets Ambiental; aqueles que buscam compreender, por meio da relação com variáveis socioeconômicas, a mudança no uso da terra (Land Use Cover Change - LUCC); outros buscam a compreensão 
do fenômeno do desmatamento por meio da análise do comportamento dos agentes microeconômicos; outros estudos consideram fatores institucionais, como estabilidade política, conflitos de terra, direitos de propriedade etc.

Entre os trabalhos empíricos que abordaram a EKC e o processo de desmatamento, variados métodos econométricos são utilizados: séries temporais, regressões com dados em corte cruzado, painel de dados, e, em menor escala, modelos econométrico-espaciais. Os resultados não são unânimes: a hipótese da EKC é verificada por alguns autores e rejeitada por outros, dependendo da escala geográfica, da região estudada e da abrangência temporal.

Até a década de 1980, o histórico do desmatamento da região da Amazônia Legal esteve ligado às ações governamentais para a ocupação e desenvolvimento do território, por intermédio de abertura de estradas e incentivo à migração (FERREIRA e SALATI, 2005; BECKER, 2005). Segundo o Plano Amazônia Sustentável, até aquela década, o desmatamento na região da Amazônia Legal alcançava cerca de $300 \mathrm{mil} \mathrm{km}^{2}$, o equivalente a 6\% da área total. De 1980 a 2007, foram desmatados mais $432 \mathrm{mil} \mathrm{km}^{2}$, correspondendo no total a quase $15 \%$ da região amazônica (BRASIL, 2008). Os condicionantes recentes do desmatamento, entretanto, apontam para as atividades agropecuárias que se expandem seguindo a lógica econômica privada (MARGULIS, 2003).

Os fatores determinantes do desmatamento da Amazônia brasileira são objeto de vasta literatura. As causas investigadas recaem sobre os temas: ambiental (qualidade de solos, pluviosidade, temperatura), socioeconômico (população urbana e rural, educação, renda, produção agrícola, preços de produtos agrícolas, características das propriedades rurais etc.) e acessibilidade (rodovias pavimentadas e não pavimentadas, distância de mercados locais e nacionais etc.).

Com relação a variáveis ambientais, a precipitação pluviométrica é considerada a mais relevante (MARGULIS, 2003; IGLIORI, 2006; CALDAS et al., 2003; CHOMITZ e THOMAS, 2003). Com relação às facilidades de acesso, todos os estudos que investigaram alguma forma dessa variável consideraram-na relevante (PFAFF, 1999; REIS e GUZMÁN, 1994; AGUIAR et al., 2007), com exceção de Margulis (2003), que não chegou a um resultado conclusivo quanto a esse aspecto.

Entre os fatores socioeconômicos, a população é considerada relevante e segue um padrão não linear, primeiro crescente e depois decrescente (IGLIORI, 2006; PFAFF, 1999). A variável renda é considerada significativa em todos os estudos, porém com fraca intensidade. A hipótese da EKC para o desmatamento da Amazônia foi verificada nos trabalhos de Gomes e Braga (2008) e Araújo et al. (2008), em nível estadual, sendo que neste último o objetivo principal era a verificação da importância de aspectos institucionais. A EKC também foi verificada, com dados municipais, por Caldas et al. (2003), Santos et al. (2008) e Prates (2008).

Em maior ou menor grau, todos os estudos consideram algum tipo de relação das atividades agropecuárias com o desmatamento. Além do trabalho 
de Margulis (2003), Miragaya (2008) reforça que a demanda por carne bovina é de longe o fator preponderante no desmatamento da região, mais do que a expansão da produção de grãos, em especial a soja, que tem sido também apontada como fator que pressiona a fronteira agrícola em direção às áreas de florestas (BROWN et al., 2005; VERA-DIAZ et al., 2008). Silva (2006) afirma que a maior parte do desmatamento amazônico até 1997 ocorreu nas terras com maior potencial agropecuário, o que está de acordo com o trabalho de Chomitz e Thomas (2003), que verifica que a conversão de terras para uso agropecuário diminui substancialmente com o aumento dos níveis de pluviosidade, tornando as áreas mais úmidas menos interessantes do ponto de vista econômico e, portanto, menos sujeitas ao avanço do desmatamento. Segundo Aguiar et al. (2007), a área convertida a pastagens corresponde a cerca de $70 \%$ da área total desmatada, e as áreas convertidas a culturas temporárias e permanentes correspondem a $13 \%$ e 3\% da área total desmatada, respectivamente.

Em geral, os trabalhos empíricos utilizaram modelos econométricos tradicionais. Ângelo e Pereira de Sá (2007) e Ewers, Laurance e Souza Jr (2008) utilizaram regressões para séries de tempo. Gomes e Braga (2008), Santos et al. (2008) e Prates (2008) utilizaram modelos econométricos de dados em painel. Os outros autores utilizaram regressões com dados em corte cruzado (em nível estadual, municipal, de setor censitário, ou gride - segmentação da área de estudo em quadrados de dimensão determinada, como, por exemplo, $25 \mathrm{~km} \times 25 \mathrm{~km}$ ).

O processo de desmatamento possui um forte componente espacial, pois trata-se de um espaço ocupado pela cobertura florestal, que é convertido em outro uso, relacionando-se com os tipos de uso da terra verificados na vizinhança das áreas desmatadas. Com base nisso, alguns estudos utilizaram modelos que consideraram os efeitos espaciais do desmatamento. Entre eles, destacam-se os trabalhos de Reis e Guzmán (1994), Caldas et al. (2003), Igliori (2006) e Aguiar et al. (2007). Estes últimos encontraram dependência espacial significativa para o desmatamento, utilizando dados em corte cruzado. A justificativa para a inclusão de variáveis relacionadas aos efeitos espaciais é dada por Alves (apud MARGULIS, 2003): o desmatamento é um processo de interação espacial, em que as áreas desmatadas são vizinhas de áreas anteriormente desmatadas.

Resumidamente, entre os estudos que investigam uma EKC para o desmatamento da região amazônica, podem ser citados os trabalhos de Caldas et al. (2003), que considera o município de Uruará (PA); Gomes e Braga (2008) e Araújo et al. (2009), que utilizam um painel de dados em nível estadual; Prates (2008) e Santos et al. (2008), que utilizam um painel de dados em nível municipal. Outros trabalhos não estimaram a relação da EKC, porém, trataram de forma importante os efeitos espaciais do desmatamento na região: Reis e Guzmán (1993), Pfaff (1999), Chomitz e Thomas (2003), Igliori (2006) e Aguiar et al. (2007). Reis e Guzmán (1993) e Igliori (2006) consideraram a dependência espacial na análise econométrica; este último autor utilizou dados em diferenças 
para 257 áreas comparáveis, levando em consideração os efeitos não observados. Quanto aos demais estudos, nenhum utilizou painel de dados incorporando o tratamento para dependência espacial. Pfaff (1999) e Chomitz e Thomas (2003) incluíram em seus modelos variáveis relativas à proximidade espacial de outras variáveis importantes, mas não utilizaram um modelo econométrico-espacial propriamente dito. Nenhum dos estudos utilizou painel de dados com tratamento para dependência espacial e heterogeneidade espacial dos parâmetros. O Quadro 1 resume os trabalhos sobre a região que consideram a EKC e/ou efeitos espaciais citados acima.

Quadro 1. Resumo dos trabalhos sobre desmatamento na Amazônia que consideram a EKC e/ou efeitos espaciais.

\begin{tabular}{|c|c|c|c|c|c|}
\hline Autor & Tipos de dados & EKC & $\begin{array}{l}\text { Efeitos não } \\
\text { observados }\end{array}$ & $\begin{array}{c}\text { Dependência } \\
\text { espacial }\end{array}$ & $\begin{array}{c}\text { Heterogeneidade } \\
\text { espacial }\end{array}$ \\
\hline $\begin{array}{c}\text { Gomes e Braga } \\
(2008)\end{array}$ & Painel (estados) & $\sqrt{ }$ & $\sqrt{ }$ & - & - \\
\hline $\begin{array}{l}\text { Araújo et al. } \\
(2008)\end{array}$ & Painel (estados) & $\sqrt{ }$ & $\sqrt{ }$ & - & - \\
\hline Igliori (2006) & $\begin{array}{c}\text { Diferença } \\
\text { (257 áreas } \\
\text { comparáveis) }\end{array}$ & - & $\sqrt{ }$ & $\sqrt{ }$ & - \\
\hline $\begin{array}{c}\text { Reis e Guzmán } \\
\text { (1993) }\end{array}$ & $\begin{array}{l}\text { Cross-section } \\
\text { (municípios) }\end{array}$ & - & - & $\sqrt{ }$ & - \\
\hline $\begin{array}{l}\text { Santos et al. } \\
(2008)\end{array}$ & $\begin{array}{c}\text { Painel } \\
\text { (municípios) }\end{array}$ & $\sqrt{ }$ & $\sqrt{ }$ & - & - \\
\hline Pfaff (1999) & $\begin{array}{c}\text { Dados agrupados } \\
\text { (municípios) }\end{array}$ & - & - & $(\sqrt{ })^{*}$ & - \\
\hline Prates (2008) & $\begin{array}{c}\text { Painel } \\
\text { (municípios) }\end{array}$ & $\sqrt{ }$ & $\sqrt{ }$ & - & $\sqrt{ }$ \\
\hline $\begin{array}{c}\text { Chomitz e } \\
\text { Thomas (2003) }\end{array}$ & $\begin{array}{c}\text { Cross-section } \\
\text { (6776 setores } \\
\text { censitários) }\end{array}$ & - & - & $(\sqrt{ })^{*}$ & - \\
\hline $\begin{array}{c}\text { Aguiar et al. } \\
\text { (2007) }\end{array}$ & $\begin{array}{l}\text { Cross-section } \\
\text { (grid } 25 \mathrm{~km} \mathrm{x} \\
25 \mathrm{~km})\end{array}$ & - & - & $\sqrt{ }$ & $\sqrt{ }$ \\
\hline $\begin{array}{l}\text { Caldas et al. } \\
\text { (2003) }\end{array}$ & $\begin{array}{c}\text { Cross-section } \\
\text { (153 pequenas } \\
\text { propriedades, } \\
\text { PA) }\end{array}$ & $\sqrt{ }$ & - & $\sqrt{ }$ & - \\
\hline
\end{tabular}

* Indica que, nestes trabalhos, foram usadas variáveis relacionadas a alguma forma de proximidade espacial, mas não exatamente tratadas como dependência espacial.

Fonte: Elaboração própria (2009). 
716 - Desmatamento e Crescimento Econômico no Brasil: uma análise da Curva de Kuznets Ambiental para a Amazônia Legal

Para a aplicação da EKC para o desmatamento, a especificação tradicional do modelo inclui a variável renda per capita e seu termo quadrático (BARBIER e BURGESS, 2002). Alguns trabalhos incluem ainda a forma cúbica e logaritmizada (GOMES e BRAGA, 2008; SANTOS et al., 2008). A especificação geral é:

$$
\text { DESMATAMENTO }=\alpha_{1}+\alpha_{2} \mathrm{Y}+\alpha_{3} \mathrm{Y}^{2}+\alpha_{4} \mathrm{Y}^{3}+\mathbf{z} \beta+\mathbf{u}
$$

onde DESMATAMENTO é a variável de interesse, $Y$ é a renda per capita, e $\mathbf{z}$ é um vetor $1 \times k$ que inclui outras variáveis explicativas para o processo de desmatamento (população, acesso, variáveis institucionais etc.), $u$ é o termo de erro aleatório, e $\alpha_{\mathrm{i}} \mathrm{e} \beta$ (vetor $k \times 1$ ) são parâmetros.

Os coeficientes $\alpha_{\mathrm{i}}$ da equação (1) determinam o formato da curva que relaciona degradação e renda (DE BRUYN et al., 1998). A Figura 1 ilustra os diferentes formatos para esta relação, adaptada para o caso do desmatamento como indicador de degradação ambiental. Pode existir uma relação linear monotônica crescente (quando $\alpha_{2}>0$ e $\alpha_{3}=\alpha_{4}=0$ ) indicando que a elevação da renda está associada a maiores níveis de desmatamento (Figura 1a); ou, ao contrário, pode existir uma relação linear monotônica decrescente $\left(\alpha_{2}<0\right.$ e $\alpha_{3}=$ $\left.\alpha_{4}=0\right)$, indicando que a elevação da renda está associada à diminuição dos níveis de desmatamento (Figura 1b). O formato de " $\mathrm{U}$ " invertido da EKC é observado quando existe uma relação quadrática (ou seja, se $\alpha_{2} \geq 0$, $\alpha_{3}<0$ e $\alpha_{4}=$ 0 ), indicando que a elevação da renda está associada a um maior desmatamento nos níveis iniciais, invertendo-se o processo a partir de um determinado ponto (Figura 1c). Ou, ainda, a relação entre desmatamento e crescimento pode-se apresentar como a forma de " $\mathrm{N}$ ", ou seja, uma relação representada por um polinômio cúbico (se $\alpha_{2} \geq 0, \alpha_{3}<0$, e $\alpha_{4}>0$ ), indicando que, após um estágio decrescente intermediário, a elevação da renda provocaria níveis de desmatamento crescentes (Figura 1e). Outras formas para essa relação, como a de "U" (Figura 1d) ou a de "N" invertido (Figura 1f), também são encontradas em literatura (CIRIACI e PALMA, 2009). 
Figura 1. Relação entre degradação ambiental e renda.
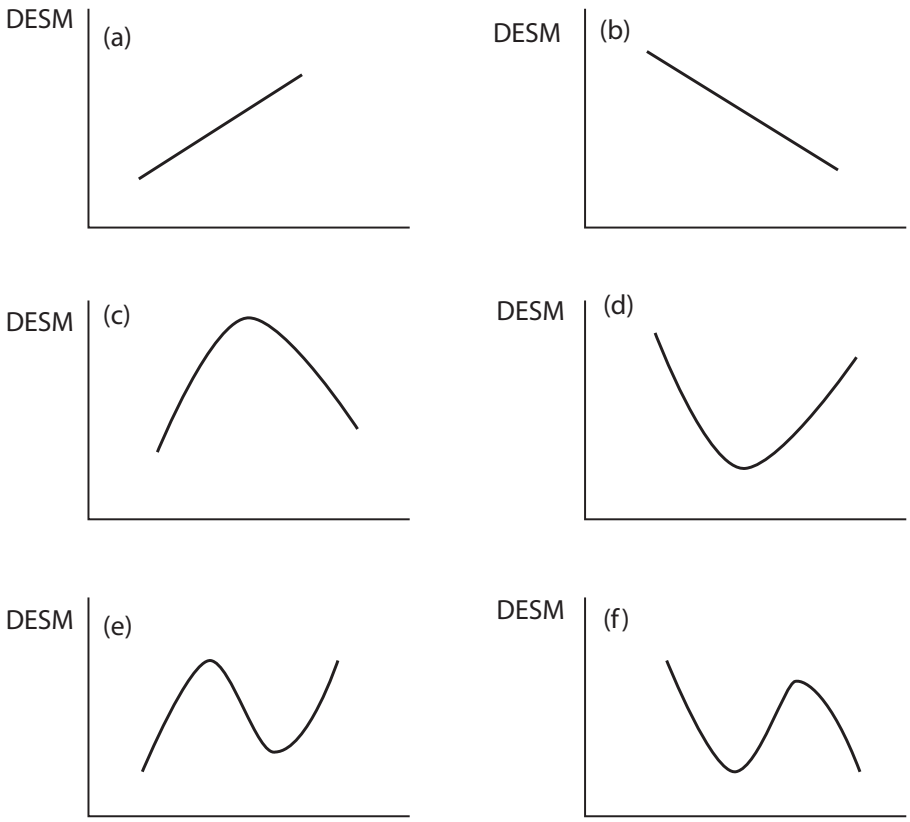

Fonte: Adaptado de Carvalho (2008).

\section{Metodologia}

Este trabalho busca identificar uma relação entre crescimento econômico e desmatamento da Amazônia Legal, como sugerida pela Curva de Kuznets Ambiental, considerando efeitos espaciais de dependência espacial. Além disso, foram acrescentadas variáveis explicativas adicionais, conforme relatadas em literatura como determinantes do desmatamento,tais como: rebanho bovino, culturas agrícolas como soja e cana-de-açúcar, extração vegetal e silvicultura, densidade populacional, crédito rural e área de floresta preexistente. Os dados da área desmatada anual são os disponíveis para os 782 municípios da região monitorados pelo Sistema Prodes (Programa de Avaliação do Desflorestamento na Amazônia Legal, Instituto Nacional de Pesquisas Espaciais - Inpe), entre 2001 e 2006, formando um painel de dados mais extenso que o de estudos anteriores (GOMES e BRAGA, 2008; SANTOS et al., 2008; PRATES, 2008). A incorporação de variáveis relacionadas a efeitos de dependência espacial no painel de dados não tem correspondente em estudos anteriores. 
A utilização de modelos de dados em painel permite a superação das limitações comuns às estimações em corte cruzado (cross-section) e em séries de tempo. Os parâmetros em corte cruzado podem se alterar ao longo do tempo sem que esse efeito seja captado pelas variáveis explicativas, assim como não é possível controlar para efeitos não observados invariantes no tempo. Os parâmetros em séries temporais trabalham com dados agregados para as variáveis explicativas e não captam as diferenças entre os indivíduos. Com dados em painel, têmse observações repetidas para os mesmo indivíduos ao longo do tempo, e os problemas característicos das estimações de corte cruzado e de séries de tempo podem ser superados, ao mesmo tempo em que o número de graus de liberdade aumenta consideravelmente (PINDYCK e RUBINFELD, 2004).

Segundo Elhorst (2003), os modelos de dados em painel comumente usados na literatura empírica podem ser expandidos para a incorporação de efeitos espaciais: dependência espacial e heterogeneidade espacial. Para duas categorias de modelos de painel de dados espaciais detalhadas pelo autor, efeitos fixos e efeitos aleatórios, o coeficiente de cada variável regressora é único e global e capta o comportamento representativo, ou "médio", entre as variáveis. A dependência espacial pode ser incorporada à especificação do modelo por meio de processo autorregressivo no termo de erro (modelo de erro espacial), ou por intermédio da variável dependente defasada espacialmente (modelo de defasagem espacial), em que o valor da variável dependente é influenciado pelo valor dessa variável nos municípios vizinhos. A heterogeneidade espacial nos modelos de dados em painel com coeficientes globais é incorporada pela variação do intercepto, representando os efeitos individuais não observados.

Primeiramente, será estimado o modelo econométrico para a EKC do desmatamento da Amazônia Legal, sem considerar os efeitos espaciais, com a seguinte especificação (modelo básico) representada na forma empilhada:

$$
\mathrm{DESM}_{\mathrm{t}}=\alpha_{1}+\alpha_{2} Y_{\mathrm{t}}+\alpha_{3} Y_{\mathrm{t}}^{2}+\alpha_{4} Y_{\mathrm{t}}^{3}+\mathbf{z}_{t} \beta_{k}+\tau \mathrm{D}_{t}+\mu+\mathbf{u}_{t}
$$

O subscrito $t$ para o painel de dados corresponde ao ano observado $t=2001,2002, \ldots, 2006$, para cada um dos $i$ municípios da região da Amazônia Legal mapeados pelo sistema Prodes/Inpe, sendo $i=1,2,3, \ldots, 782 ; \mathbf{z}$ corresponde ao vetor com $k$ variáveis regressoras adicionais ao termo tradicional da EKC, a saber, BOV, SOJA, CANA, EXT_MAD, EXT_NMAD, SILV_MAD, DPOP, CR e FLO. Os dados compõem um painel balanceado com4.692 observações. O Quadro 2 descreve as variáveis incluídas no modelo. Adicionalmente, $\mu$ são os efeitos individuais (relacionadas a características do município, praticamente invariantes no tempo, tais como topografia, áreas protegidas, distância a mercados e outras), $\mathrm{D}_{\mathrm{t}}$ são variáveis dummies anuais para captarem os efeitos temporais, sendo que $\tau$ é um vetor de coeficientes associado a essas dummies; $\mathrm{u}_{\mathrm{t}}$ é o termo de erro aleatório, e $\alpha_{1, \ldots, 4} \mathrm{e} \beta_{1, \ldots, 9}$ são parâmetros a serem estimados.

O PIB per capita ao quadrado é incluído para testar a hipótese da EKC de que o desmatamento cresce a taxas decrescentes para níveis mais baixos de 
renda, e a partir de determinado ponto, a elevação do nível de renda reduz o desmatamento. O termo cúbico do PIB per capita é incluído para testar se essa relação segue uma forma de " $\mathrm{N}$ ", ou seja, após a redução, o desmatamento volta a aumentar com o nível de renda.

Quadro 2. Descrição das variáveis utilizadas no modelo empírico.

\begin{tabular}{|c|c|c|c|c|c|}
\hline & Variável & Descrição & Unidade & \begin{tabular}{|c|}
$\begin{array}{c}\text { Sinal es- } \\
\text { perado do } \\
\text { coeficiente }^{*}\end{array}$ \\
\end{tabular} & $\begin{array}{l}\text { Fonte dos } \\
\text { dados }\end{array}$ \\
\hline \begin{tabular}{|c|} 
Variável \\
dependente
\end{tabular} & DESM & $\begin{array}{l}\text { Incremento anual } \\
\text { da área desmatada }\end{array}$ & $\mathrm{km}^{2}$ & - & Prodes/Inpe ${ }^{1}$ \\
\hline \multirow{3}{*}{$\begin{array}{c}\text { Variáveis } \\
\text { explicativas } \\
\text { (EKC) }\end{array}$} & $\mathrm{Y}$ & $\begin{array}{l}\text { PIB per capita } \\
\text { municipal }\end{array}$ & $\mathrm{R} \$$ de 2000 & Positivo & IBGE $^{2}$ \\
\hline & Y2 & $\begin{array}{l}\text { PIB per capita muni- } \\
\text { cipal ao quadrado }\end{array}$ & $\begin{array}{l}\text { (R\$ de 2000) } \\
\text { ao quadrado }\end{array}$ & Negativo & $\begin{array}{l}\text { Calculada a } \\
\text { partir de Y }\end{array}$ \\
\hline & Y3 & $\begin{array}{c}\text { PIB per capita } \\
\text { municipal ao cubo }\end{array}$ & $\begin{array}{l}\text { (R\$ de } 2000) \\
\text { ao cubo }\end{array}$ & Nulo & $\begin{array}{l}\text { Calculada a } \\
\text { partir de Y }\end{array}$ \\
\hline \multirow{9}{*}{$\begin{array}{c}\text { Variáveis } \\
\text { explicativas } \\
\text { adicionais } \\
(\mathrm{z})\end{array}$} & $\mathrm{BOV}$ & Rebanho bovino & unidade & Positivo & $\mathrm{PPM}^{3} / \mathrm{IBGE}$ \\
\hline & SOJA & $\begin{array}{c}\text { Área plantada } \\
\text { de soja }\end{array}$ & hectare & Positivo & $\mathrm{PAM}^{4} / \mathrm{IBGE}$ \\
\hline & CANA & $\begin{array}{l}\text { Área plantada de } \\
\text { cana-de-açúcar }\end{array}$ & hectare & Positivo & PAM/IBGE \\
\hline & EXT_MAD & \begin{tabular}{|c|}
$\begin{array}{c}\text { Extração de madeira } \\
\text { (carvão vegetal, } \\
\text { lenha e tora) }\end{array}$ \\
\end{tabular} & $\mathrm{m}^{3}$ & Positivo & PEVS $5 /$ IBGE \\
\hline & EXT_NMAD & \begin{tabular}{|c|}
$\begin{array}{c}\text { Extração vegetal } \\
\text { de produtos não } \\
\text { madeireiros }\end{array}$ \\
\end{tabular} & tonelada & Negativo & PEVS/IBGE \\
\hline & SILV_MAD & $\begin{array}{c}\text { Silvicultura } \\
\text { (madeira) }\end{array}$ & $\mathrm{m}^{3}$ & Negativo & PEVS/IBGE \\
\hline & DPOP & $\begin{array}{l}\text { Densidade } \\
\text { populacional }\end{array}$ & $\begin{array}{l}\text { número de } \\
\text { habitantes/ } \\
\mathrm{km}^{2}\end{array}$ & Positivo & IBGE \\
\hline & $\mathrm{CR}$ & Crédito rural & $\mathrm{R} \$$ de 2000 & Positivo & Banco Central \\
\hline & FLO & $\begin{array}{l}\text { Área de floresta } \\
\text { em }(t-1)\end{array}$ & $\mathrm{km}^{2}$ & & Prodes/Inpe \\
\hline
\end{tabular}

*Nota: A significância dos coeficientes é testada em $5 \%$.

1. Disponível em http://www.dpi.inpe.br/prodesdigital/prodesmunicipal.php

2. Disponível em http://www.ipeadata.gov.br

3. Produção Pecuária Municipal. Disponível em http://www.sidra.ibge.gov.br

4. Produção Agrícola Municipal. Disponível em http://www.sidra.ibge.gov.br

5. Produção da Extração Vegetal e da Silvicultura. Disponível em http://www.sidra.ibge.gov.br Fonte: Elaboração própria (2009). 
O modelo sem correção para efeitos espaciais especificado acima (modelo básico) é estimado pelo método de efeitos fixos e efeitos aleatórios e por Mínimos Quadrados Ordinários (MQO) com dados agrupados (pooled). Os critérios de avaliação são os testes de Breusch-Pagan, F e Hausman (BAUM, 2006). Para a identificação do modelo, o termo de erro não deve estar correlacionado com as variáveis explicativas (WOOLDRIDGE, 2002).

Os resultados para o modelo sem efeitos espaciais (modelo básico) são usados em comparação com os modelos econométricos que incluem dependência espacial, descritos a seguir. Segundo Almeida (2008), a dependência espacial pode estar presente no termo de erro, na variável dependente e/ou na variável explicativa. Sua inclusão no modelo depende da definição do arranjo espacial das observações, expressa pela matriz de pesos espaciais $W$. Os pesos são não nulos quando as observações são contíguas, ou quando estão dentro de uma certa distância uma da outra. A matriz de pesos espaciais contém a informação de quanto a interação é mais forte no caso de regiões próximas (geograficamente ou economicamente), e mais fraca no caso de regióes mais distantes.

Há várias formas alternativas de se definir a matriz de pesos espaciais: com base na contiguidade (formato "torre", com lados em comum, ou "rainha", com lados e arestas em comum), na distância geográfica, no inverso da distância, matriz binária com $k$ vizinhos mais próximos (baseado em uma distância crítica definida para cada região para que tenha exatamente um número determinado de vizinhos $-k$ ). A matriz de pesos espaciais $W$ é escolhida com base na avaliação da autocorrelação espacial dos resíduos do modelo básico, seguindo o procedimento de Baumont (2004), que sugere que a escolha da matriz espacial seja sobre aquela capaz de captar maiores efeitos espaciais nos resíduos (indicado pelo maior valor de I de Moran).

Os modelos de dados em painel com dependência espacial são testados nas especificações relacionadas no Quadro 3, onde também são relacionados os métodos de estimação. Se a dependência espacial estiver presente no termo de erro, tem-se o modelo de erro espacial; caso a dependência espacial esteja presente na variável dependente, tem-se o modelo de defasagem espacial. Neste último caso, a variável dependente defasada espacialmente é endógena, uma vez que é altamente correlacionada com o termo de erro. Assim, no caso de efeitos fixos, as equações onde o termo $W_{1} y_{t}$ aparece devem ser estimadas utilizando-se o estimador within com variáveis instrumentais, pelo método de Mínimos Quadrados em Dois Estágios (MQ2E). As variáveis instrumentais indicadas são as variáveis explicativas e suas defasagens espaciais que, a princípio, possuem alta correlação com a variável dependente e não possuem correlação com o termo de erro (KELEJIAN e PRUCHA, 1998). A estimação das equações com o termo de erro defasado espacialmente deve ser feita por máxima verossimilhança, no caso de erros com distribuição normal, ou pelo método generalizado dos momentos - MGM, que prescinde da normalidade dos erros 
(LEE, 2007; BELL e BOCKSTAEL, 2000). A dependência espacial pode também estar presente na variável explicativa, no caso do modelo de transbordamentos espaciais ou regressivo cruzado espacial, onde o estimador within é o mais apropriado, no caso da presença de efeitos fixos.

Os resultados dos modelos de dados em painel com dependência espacial são avaliados com base na remoção da autocorrelação espacial dos resíduos dos cortes cruzados de cada ano de observação e, entre os modelos que atenderem este critério, é escolhido o que se ajusta melhor aos dados observados, com base no Critério de Informação de Akaike (menor AIC). Antes, porém, é feita uma análise exploratória de dados espaciais, com o mapeamento dos padrões de associação espacial.

Para uma identificação adequada do modelo, deve-se atentar para as fontes de má-especificação relacionadas na literatura (WOOLDRIDGE, 2002; ALMEIDA, 2008), a saber:

a. Viés de seleção;

b. Erro de medida nas variáveis;

c. Omissão de variáveis observáveis relevantes;

d. Omissão de variáveis não observáveis relevantes;

e. Dependência espacial;

f. Forma funcional errada.

Este trabalho utiliza dados de todos os municípios da região da Amazônia Legal, ou seja, dados referentes a toda a população, o que resolve a primeira fonte de má-especificação relacionada, viés de seleção. A segunda fonte de má-especificação, erro de medida nas variáveis, é minimizada pela escolha da abrangência temporal: a partir de 2000, tem-se a revisão metodológica para os dados de área desmatada provenientes do sistema Prodes (Inpe) e, a partir de 2001, a malha municipal da região não sofre grandes alterações. Os dados de área desmatada, entretanto, não computam áreas com regeneração florestal, que podem ser novamente desmatadas ou não, o que seria importante para representar a dinâmica de abandono e retomada das terras para atividades produtivas (lavoura e pastagens). Essas áreas de matas secundárias chegam a $20 \%$ da floresta desmatada, em estimativa preliminar do Inpe, e serão monitoradas anualmente a partir de 2009 (INPE, 2009), não estando estes dados disponíveis para o período deste estudo.

A terceira fonte de má-especificação relacionada, a omissão de variáveis observáveis relevantes, é tratada com a inclusão das variáveis explicativas adicionais ao termo da EKC (Quadro 2), buscando-se identificar a relação entre o desmatamento da região e as atividades agropecuárias.

A omissão de variáveis não observáveis relevantes, outra fonte de má-especificação, é minimizada com a utilização de dados em painel, que trata a omissão de variáveis relevantes que não variam no tempo de análise. 
Desmatamento e Crescimento Econômico no Brasil:

uma análise da Curva de Kuznets Ambiental para a Amazônia Legal

Consideram-se, entre estas últimas, as características do município praticamente invariantes no tempo do estudo, tais como topografia, áreas protegidas, distância a mercados, proximidade de rodovias etc., que são variáveis relacionadas ao desmatamento em estudos anteriores que usaram dados em cross-section (vide seção 2). Para tratar a quinta fonte de má-especificação relacionada, serão utilizados procedimentos econométricos que levam em consideração os efeitos de dependência espacial gerados pelo processo de desmatamento (modelos de dados em painel com dependência espacial). A última fonte de má-especificação citada, forma funcional errada, foi objeto de investigação em trabalho anterior.

Os softwares utilizados para a análise exploratória de dados espaciais foram: Spacestat (e Arcview) e GeoDa. Os softwares utilizados para estimação dos modelos foram: Stata 9 e Eviews 6.

A Tabela 1 apresenta uma estatística descritiva dos dados. O apêndice A apresenta a tabela de correlação entre as variáveis.

Tabela 1. Estatística descritiva dos dados.

\begin{tabular}{ccccc}
\hline Variável & Média & Desvio padrão & Mínimo & Máximo \\
\hline DESM & 40,47 & 137,28 & 0,00 & $4.673,20$ \\
Y & $3.665,34$ & $5.116,78$ & 579,91 & $84.496,32$ \\
Y2 & $3,96 \mathrm{E}+07$ & $2,63 \mathrm{E}+08$ & $3,36 \mathrm{E}+05$ & $7,14 \mathrm{E}+09$ \\
Y3 & $1,33 \mathrm{E}+12$ & $1,72 \mathrm{E}+13$ & $1,95 \mathrm{E}+08$ & $6,03 \mathrm{E}+14$ \\
BOV & $83.340,74$ & $124.998,20$ & 0,00 & $1.596 .411,00$ \\
SOJA & $6.698,75$ & $35.279,23$ & 0,00 & $596.658,00$ \\
CANA & 296,68 & $2.316,42$ & 0,00 & $42.452,00$ \\
EXT_MAD & $40.769,77$ & $119.464,60$ & 0,00 & $2.988 .000,00$ \\
EXT_NMAD & 354,65 & $1.419,75$ & 0,00 & $32.039,00$ \\
SILV_MAD & $2.671,30$ & $47.852,79$ & 0,00 & $1.825 .789,00$ \\
DPOP & 21,54 & 115,87 & 0,11 & $2.692,41$ \\
CR & $3,55 \mathrm{E}+06$ & $9,96 \mathrm{E}+06$ & 0,00 & $1,51 \mathrm{E}+08$ \\
FLO & $4.335,08$ & $12.691,78$ & 0,00 & $152.235,10$ \\
\hline
\end{tabular}

Fonte: Dados da pesquisa. 
Rejane Corrêa de Oliveira, Eduardo Almeida, Ricardo da Silva Freguglia e 723 Ricardo Candéa Sá Barreto

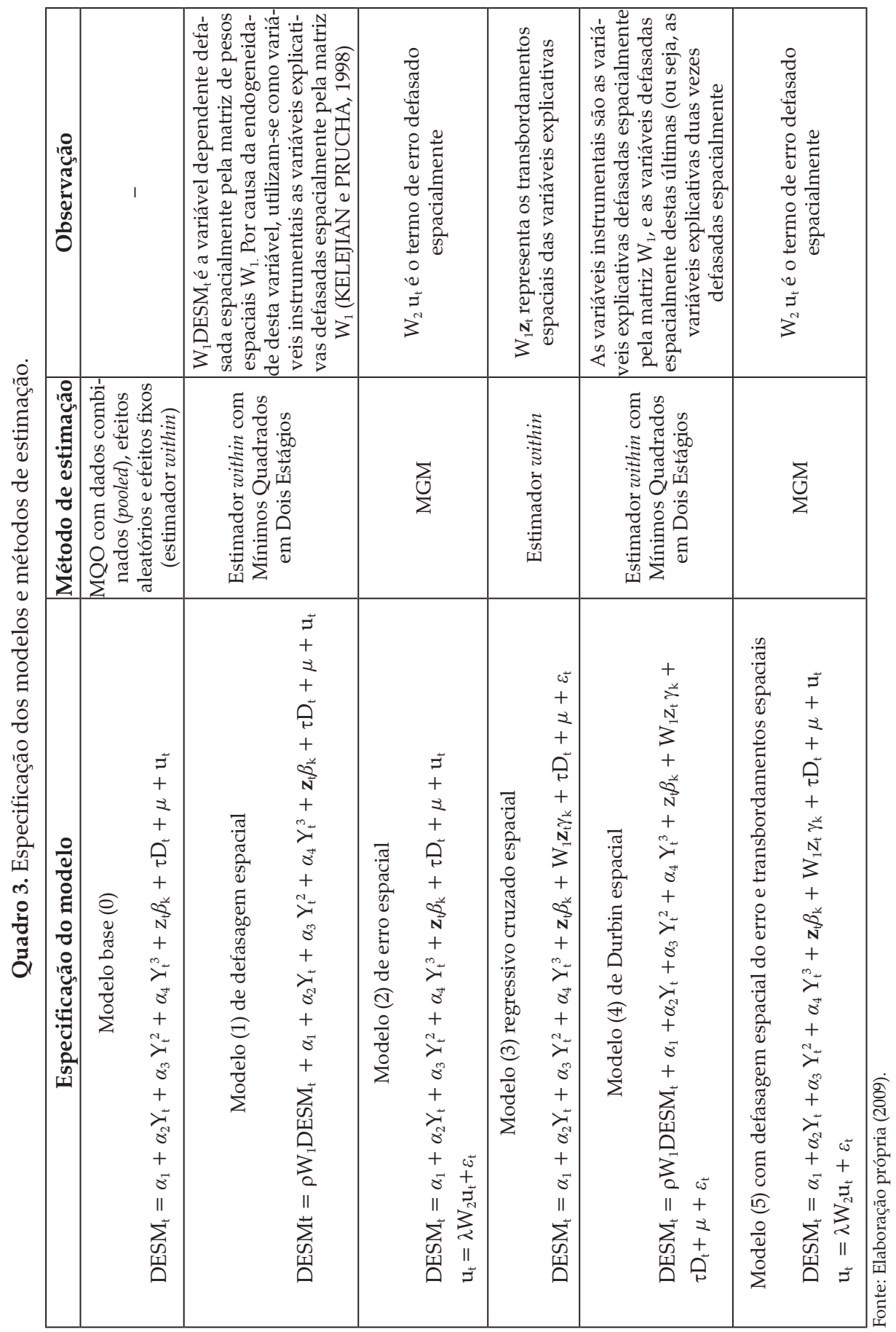

RESR, Piracicaba, SP, vol. 49, no 03, p. 709-740, jul/set 2011 - Impressa em novembro 2011 
724 - Desmatamento e Crescimento Econômico no Brasil: uma análise da Curva de Kuznets Ambiental para a Amazônia Legal

\section{Resultados e discussão}

\subsection{Análise exploratória de dados espaciais}

A Análise Exploratória de Dados Espaciais (Aede) mostrou a presença de autocorrelação espacial global para o desmatamento na região, em um padrão de concentração: o menor valor para o I de Moran foi de 0,4132 em 2006, e o maior valor foi de 0,5187 , em 2004. O Mapa 1 indica a existência de clusters do tipo Alto-Alto em parte do Arco do Povoamento Adensado e parte da Amazônia Central, isto é, agrupamentos de municípios com altos valores de desmatamento próximos a municípios que apresentam também altos valores de área desmatada no período. A Aede realizada para o contexto bivariado (área desmatada anual e PIB per capita municipal) mostra resultados mais diversos do que os encontrados no contexto univariado (veja Mapa 2). O grande cluster do desmatamento na região central do Arco do Povoamento Adensado e Amazônia Central apresenta dois padrões distintos de relação com o PIB per capita:

1. A porção que abrange o estado de Mato Grosso e sudeste do Pará apresenta um padrão de associação local Alto-Alto, ou seja, os municípios com alto PIB per capita são vizinhos de municípios com alto desmatamento;

2. O restante do estado do Pará e Amazonas apresenta padrões de associação local Baixo-Alto, ou seja, municípios com menores valores para o PIB per capita são rodeados por municípios com alto desmatamento.

Outros pequenos clusters com outros padrões de associação são também observados. De modo global, a autocorrelação espacial bivariada ocorre no padrão de concentração, porém com menor intensidade (menores valores para oI de Moran - entre 0,0548 e 0,1379 ) do que no contexto univariado. 
Figura 2. Mapa de clusters para a área desmatada dos municípios da Amazônia Legal, 2006.

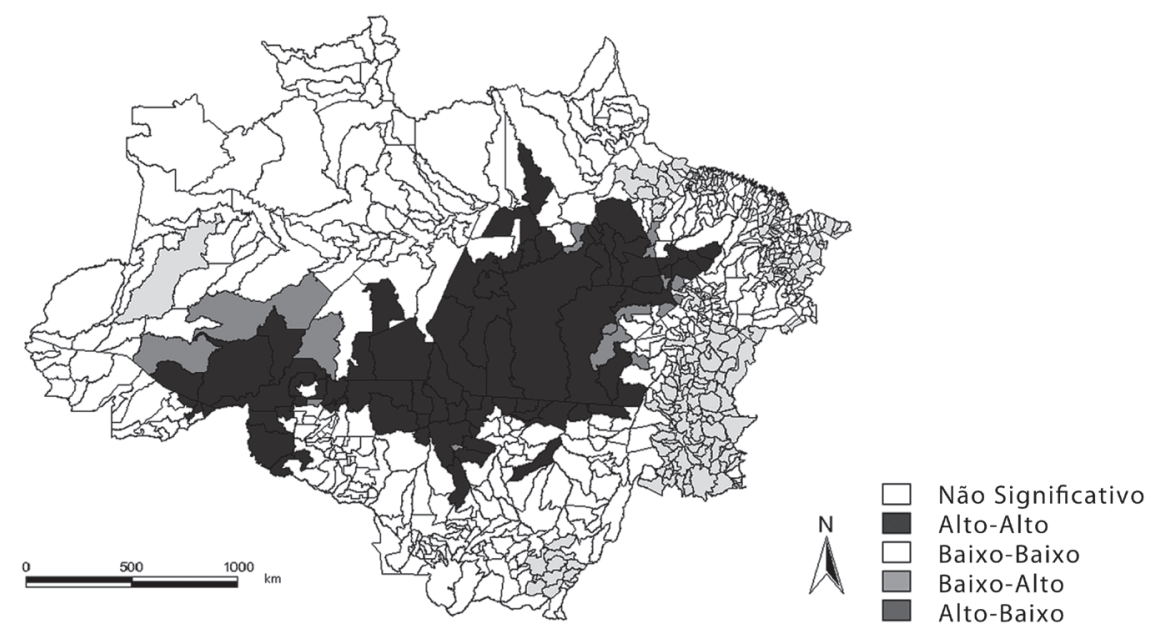

Fonte: Resultados da pesquisa.

Figura 3. Mapa de clusters bivariados para a área desmatada anual e o PIB per capita dos municípios da Amazônia Legal, 2006.

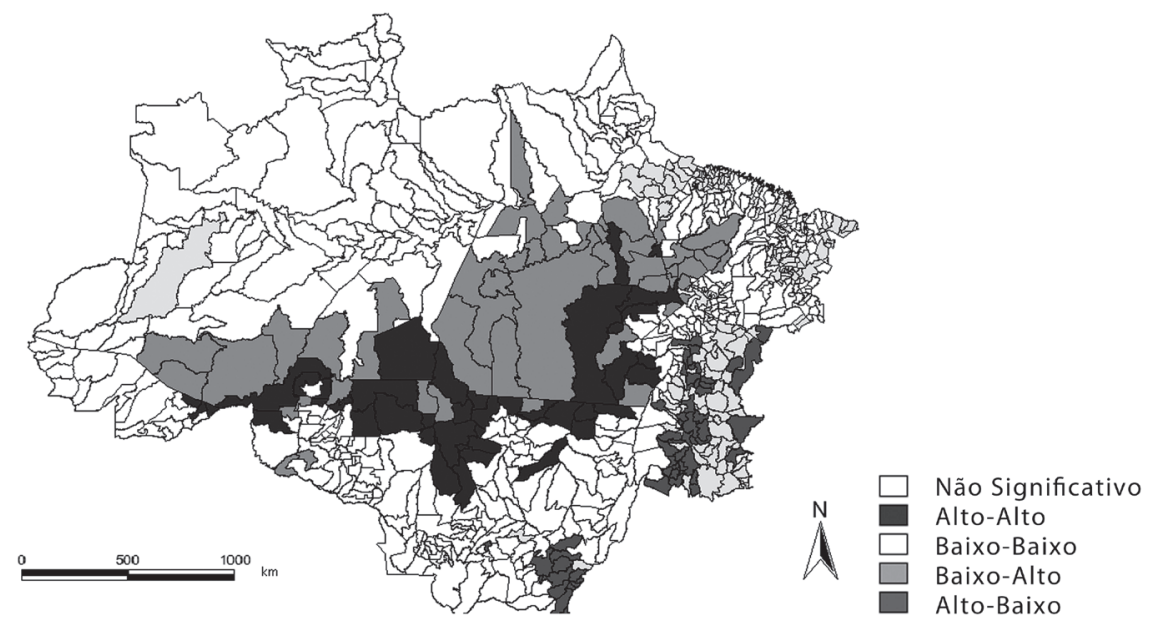

Fonte: Resultados da pesquisa. 
Desmatamento e Crescimento Econômico no Brasil: uma análise da Curva de Kuznets Ambiental para a Amazônia Legal

\subsection{Resultados dos modelos de base}

Esta subseção e a próxima (subseção 4.3) apresentam as equações estimadas para o conjunto de dados relativo aos 782 municípios da Amazônia Legal, monitorados pelo sistema Prodes (Inpe) para detecção do incremento anual da área desmatada na região, no período de 2001 a 2006. Os modelos estimados são os relacionados na seção anterior, a saber: (0) modelo sem correção para dependência espacial, (1) modelo de defasagem espacial, (2) modelo de erro espacial, (3) modelo regressivo cruzado espacial, (4) modelo de Durbin espacial, e (5) modelo de erro espacial e transbordamentos espaciais.

O modelo (0) sem correção para dependência espacial, considerado o modelo-base, foi estimado por:

1. MQO com os dados combinados (pooledOLS);

2. Considerando efeitos aleatórios em dados em painel por meio de Mínimos Quadrados Generalizados Exequíveis (MQGE);

3. Considerando efeitos fixos por meio do estimador within. A Tabela 2 apresenta os resultados obtidos para estas estimações, bem como os resultados para os testes de Breusch-Pagan, F e Hausman.

De acordo com estes resultados, o modelo que considera efeitos não observados mostra-se mais adequado do que o estimado por MQO: o teste de Breusch-Pagan para efeitos não observados apresenta-se significativo, assim, rejeita-se a hipótese nula de que a variância dos efeitos não observados é zero. Nesse caso, ao não considerar os efeitos não observados, as estimativas por MQO são inconsistentes e enviesadas. Também, o modelo estimado por efeitos fixos é preferível ao modelo de dados agrupados estimado por MQO: o resultado do teste $F$ indica que deve ser rejeitada a hipótese nula de que são corretas as restrições de interceptos iguais para ambos os modelos. Além disso, quando comparado com o modelo estimado por MQO, o modelo estimado por efeitos fixos apresenta menor valor para o critério de informação de Akaike (10.928 contra 5.199, respectivamente), indicando melhor ajuste deste último modelo. 
Tabela 2. Resultados dos modelos estimados para a Amazônia Legal (sem correção para dependência espacial).

\begin{tabular}{|c|c|c|c|}
\hline Variável & $\begin{array}{c}\text { Coeficientes } \\
\text { estimados por MQO }\end{array}$ & $\begin{array}{c}\text { Coeficientes } \\
\text { estimados por } \\
\text { efeitos aleatórios }\end{array}$ & $\begin{array}{l}\text { Coeficientes } \\
\text { estimados por } \\
\text { efeitos fixos }\end{array}$ \\
\hline Constante & $49,3231^{* * *}$ & $43,9638^{* * *}$ & $-1450,9080^{* * *}$ \\
\hline Y & $-0,0037^{* * *}$ & $-0,0006$ & 0,0001 \\
\hline $\mathrm{Y} 2$ & $1,49 \mathrm{E}-07^{* * *}$ & 5,75E-08 & 7,49E-09 \\
\hline Y3 & $-1,30 \mathrm{E}-12^{* *}$ & $-5,34 \mathrm{E}-13$ & $-7,98 \mathrm{E}-14$ \\
\hline $\mathrm{BOV}$ & $1,55 \mathrm{E}-04^{* * *}$ & $1,09 \mathrm{E}-04^{* * *}$ & $9,08 \mathrm{E}-04^{* * *}$ \\
\hline SOJA & 1,01E-04 & $-5,06 \mathrm{E}-05$ & $1,20 \mathrm{E}-03^{* *}$ \\
\hline CANA & $1,58 \mathrm{E}-04$ & 1,91E-04 & $-3,51 \mathrm{E}-04$ \\
\hline EXT_MAD & $1,45 \mathrm{E}-04^{* * *}$ & $1,72 \mathrm{E}-04^{* * *}$ & $1,65 \mathrm{E}-04^{* * *}$ \\
\hline EXT_NMAD & 2,19E-05 & $1,40 \mathrm{E}-04$ & -2,93E-04 \\
\hline SILV_MAD & $-6,02 \mathrm{E}-05^{*}$ & $-6,32 \mathrm{E}-05^{*}$ & $7,06 \mathrm{E}-06$ \\
\hline DPOP & 9,97E-03 & 8,97E-03 & $-3,58 \mathrm{E}-02$ \\
\hline $\mathrm{CR}$ & $-2,65 \mathrm{E}-07$ & -2,33E-08 & $6,22 \mathrm{E}-07^{*}$ \\
\hline FLO & $8,02 \mathrm{E}-04^{* * *}$ & $8,59 \mathrm{E}-04^{* * *}$ & $3,23 \mathrm{E}-01^{* * *}$ \\
\hline OUTLIER & $243,3816^{* * *}$ & $244,7520^{* * *}$ & $203,2089^{* * *}$ \\
\hline D2002 & $-52,8469 * * *$ & $-53,8463^{* * *}$ & $-33,9613^{* * *}$ \\
\hline D2003 & $-45,7166^{* * *}$ & $-46,9970^{* * *}$ & $-24,6319 * * *$ \\
\hline D2004 & $-45,6004^{* * *}$ & $-46,8020^{* * *}$ & $-22,1579 * * *$ \\
\hline D2005 & $-56,8358^{* * *}$ & $-57,4293^{* * *}$ & $-21,6843^{* * *}$ \\
\hline D2006 & $-64,5606^{* * *}$ & $-65,0956^{* * *}$ & $-7,2338^{* * *}$ \\
\hline $\begin{array}{l}\text { Número de } \\
\text { observações }\end{array}$ & 4692 & 4692 & 4692 \\
\hline AIC & 10928 & & 5199 \\
\hline $\mathrm{R}^{2}$ ajustado & & & 0,6699 \\
\hline $\begin{array}{l}\text { Teste de Breusch- } \\
\text {-Pagan }\end{array}$ & & $86,46^{* * *}$ & \\
\hline TesteF & & & $5,4890^{* * *}$ \\
\hline Teste de Hausman & & & $2117,21^{* * *}$ \\
\hline
\end{tabular}

* $p$-valor $<0,10$; ** $p$-valor $<0,05 ; * * *$-valor $<0,01$.

OUTLIER representa uma variável dummy para os municípios considerados outliers superiores em área desmatada anual, detectados na Aede.

Fonte: Resultados da pesquisa. 
O modelo de efeitos aleatórios foi comparado ao modelo estimado por efeitos fixos por meio do teste de Hausman (Tabela 2). A hipótese nula do teste de que não há diferença sistemática nos coeficientes estimados pelos dois métodos (e, portanto, as estimativas por efeitos aleatórios seriam consistentes), é rejeitada com 1\% de significância. Assim, o modelo estimado por efeitos fixos é favorecido em detrimento do modelo que considera efeitos aleatórios. Este resultado está de acordo com o esperado, pois muitos dos determinantes do desmatamento são características peculiares ao município e praticamente invariantes no período de estudo, tais como potencial agropecuário do solo (SILVA, 2006), pluviosidade (CHOMITZ e THOMAS, 2003), áreas protegidas (TRANCOSO et al., 2005; FERREIRA et al., 2005, VITEL et al., 2009), distância de mercados (PFAFF, 1999). Além disso, neste artigo, trabalha-se com a população de municípios da Amazônia Legal e não com uma amostra aleatória.

Os seguintes resultados são obtidos com o modelo estimado por efeitos fixos: as variáveis relativas ao rebanho bovino (BOV), soja (SOJA), crédito rural (CR) e extração de produtos madeireiros (EXT_MAD) são significativas e apresentam os coeficientes com o sinal esperado (positivo). A variável relativa à área de floresta anterior (FLO) é também significativa e positivamente correlacionada ao incremento anual do desmatamento, indicando que o desmatamento anual é maior onde há maior área de floresta preexistente. Este resultado também indica que o desmatamento anual é menor onde há pouca área de floresta (a desmatar), o que representa um efeito inercial do processo de desmatamento.

A relação entre desmatamento anual e PIB per capita municipal (Y, Y2, Y3) não é significativa, não se verificando, portanto, a hipótese da EKC no âmbito da Amazônia Legal para o período em estudo. Todas as variáveis dummies temporais se apresentaram significativas e com sinal negativo em relação ao ano de 2001. A heterogeneidade espacial não observável da região está contemplada por meio dos interceptos destas estimações de dados em painel.

Uma variável dummy (OUTLIER) foi incluída para captar os efeitos dos outliers superiores, que, na Análise Exploratória de Dados Espaciais, demonstraram ser pontos de alavancagem, isto é, reforçam o padrão de desmatamento observado. Em todos os modelos, esta variável mostrou-se significativa.

Quanto à identificação do modelo, cumpre-se a primeira hipótese que assume que o termo de erro não está correlacionado com as variáveis explicativas. A Tabela 3 apresenta os valores de correlação entre os resíduos do modelo estimado por efeitos fixos e as variáveis explicativas: para todas as variáveis o valor da correlação é zero, indicando que não há problemas de endogeneidade com as variáveis explicativas consideradas até o momento. 
Tabela 3. Correlação entre as variáveis explicativas e os resíduos da equação estimada por efeitos fixos para a Amazônia Legal.

\begin{tabular}{cc}
\hline Correlação & Resíduos \\
\hline Variáveis & 0,0000 \\
Y 2 & 0,0000 \\
Y3 & 0,0000 \\
BOV & 0,0000 \\
SOJA & 0,0000 \\
CANA & 0,0000 \\
EXT_MAD & 0,0000 \\
EXT_NMAD & 0,0000 \\
SILV_MAD & 0,0000 \\
DPOP & 0,0000 \\
CR & 0,0000 \\
FLO & 0,0000 \\
\hline
\end{tabular}

Fonte: Resultados da pesquisa.

\subsection{Resultados dos modelos com correção para dependência espacial}

A importância da estimação dos modelos com correção para a dependência espacial foi detectada por meio da análise dos resíduos do modelo-base estimado por efeitos fixos, apresentado na subseção anterior. O teste de I de Moran indicou a presença de autocorrelação espacial nos resíduos de todos os anos analisados. Assim, mostra-se relevante a estimação de modelos com correção para a dependência espacial encontrada nos resíduos. Em função da não normalidade dos resíduos indicada pelo teste de Jarque-Bera para o modelo-base estimado para cada ano separadamente, o modelo de erro espacial foi estimado pelo Método Generalizado dos Momentos (MGM), e não por máxima verossimilhança (BELL e BOCKSTAEL, 2000; LEE, 2007). Além disso, o teste de Koenker-Bassett para avaliação de heterocedasticidade indica a presença desta para todos os anos; assim, todos os modelos são estimados com correção da matriz de White. 
Para os modelos espaciais, inicialmente, são geradas as variáveis defasadas espacialmente por meio da operação da matriz de pesos espaciais sobre as variáveis dependente, explicativas e resíduos da regressão por efeitos fixos. A escolha da matriz de pesos espaciais seguiu o procedimento de Baumont (2004) para comparar os valores de $I$ de Moran obtidos com o uso das matrizes de ponderação espacial baseadas na distância, distância inversa, distância inversa ao quadrado, matrizes de contiguidade (torre e rainha), além das matrizes de $k$-vizinhos. Os resultados indicaram que a autocorrelação espacial dos resíduos da regressão é melhor captada com as matrizes torre e $k$-vizinhos igual a 2 (para as quais foram obtidos os maiores valores de $I$ de Moran), para os períodos analisados (2001 a 2006). Assim, as variáveis dependente e explicativas foram defasadas espacialmente com a matriz de pesos espaciais torre (indicada como $W_{1}$ na especificação dos modelos), enquanto os resíduos da regressão foram defasados espacialmente com a matriz de pesos espaciais de $k$-vizinhos igual a 2 (indicada como $W_{2}$ nas equações especificadas).

Os resultados numéricos são apresentados na Tabela 4. Entre todos os modelos estimados para a região da Amazônia Legal, considerada integralmente, o modelo que melhor se ajusta aos dados é o modelo de erro espacial com transbordamentos espaciais (modelo 5). O modelo (5) apresenta como variáveis significativas as indicadas pelo modelo-base estimado por efeitos fixos, com exceção da SOJA e extração de produtos madeireiros (EXT_MAD), ou seja, as variáveis relativas ao rebanho bovino, crédito rural e área de floresta anterior (BOV, CR e FLO), já discutidas acima. Além delas, são significativas as variáveis relativas ao PIB municipal per capita (Y2, Y3), indicando a presença de uma relação na forma de " $\mathrm{N}$ " invertido.

As variáveis relativas à renda defasadas espacialmente (WY, WY2 e WY3) significativas indicam que o desmatamento em um município é influenciado pela vizinhança de uma relação na forma de "N". As variáveis WSOJA, WBOV e WCR são significativas e apresentam coeficientes positivos, indicando que o cultivo de soja, a pecuária e o crédito rural em municípios vizinhos contribuem para o desmatamento em determinado município. Ao contrário, as variáveis WCANA e WEXTNM se apresentam negativamente relacionadas ao desmatamento, indicando que a presença de atividades de cultivo de cana-de-açúcar e extração de produtos não madeireiros nos municípios vizinhos contribui para um menor desmatamento. $\mathrm{O}$ parâmetro $\lambda$ do termo de erro espacial é significativo e positivo. O valor do AIC é o segundo menor entre todos os modelos para os quais este critério de informação foi calculado (4701). A análise dos resíduos pelo I de Moran indica a remoção da dependência espacial para todos os anos estudados para pelo menos uma matriz de ponderação espacial, com exceção de 2006. 
Tabela 4. Resultados das equações estimadas para a Amazônia Legal (com correção para dependência espacial).

\begin{tabular}{|c|c|c|c|c|c|}
\hline & Modelo (1) & Modelo (2) & Modelo (3) & Modelo (4) & Modelo (5) \\
\hline$\rho$ & 0,0348 & - & - & 0,2765 & - \\
\hline$\lambda$ & - & $0,4484^{* * *}$ & - & - & $0,4832^{* * *}$ \\
\hline constante & $-1431,1683^{* *}$ & $-1481,0294^{* * *}$ & $-1500,4101^{* * *}$ & $-1014,9219$ & $-1559,3875^{* * *}$ \\
\hline $\mathrm{Y}$ & $-0,0002$ & 0,0004 & $-0,0021$ & $-0,0027$ & $-0,0024$ \\
\hline Y2 & 1,27E-08 & $-8,36 \mathrm{E}-09$ & 7,32E-08 & $9,16 \mathrm{E}-08^{*}$ & $8,24 \mathrm{E}-08^{*}$ \\
\hline Y3 & $-1,18 \mathrm{E}-13$ & $5,28 \mathrm{E}-14$ & $-5,88 \mathrm{E}-13$ & $-7,40 \mathrm{E}-13^{*}$ & $-7,11 \mathrm{E}-13^{* *}$ \\
\hline $\mathrm{BOV}$ & $0,0009^{*}$ & $0,0011^{* * *}$ & $0,0008^{*}$ & 0,0008 & $0,0007^{* * *}$ \\
\hline SOJA & 0,0012 & $0,0011^{* *}$ & 0,0007 & 0,0007 & 0,0008 \\
\hline CANA & $-0,0003$ & $-0,0035^{* *}$ & $-0,0007$ & $1,36 \mathrm{E}-05$ & $-0,0011$ \\
\hline EXT_MAD & 0,0002 & $-0,0001$ & 0,0002 & 0,0002 & 0,0002 \\
\hline EXT_NMAD & $-0,0003$ & $-0,0001$ & $-0,0002$ & $-0,0003^{* *}$ & $-1,20 \mathrm{E}-05$ \\
\hline SILV_MAD & 8,59E-06 & 0,0000 & 0,0000 & 0,0000 & 8,99E-06 \\
\hline DPOP & $-0,0389$ & $-0,0308$ & 0,0039 & $-0,0109$ & $-0,0001$ \\
\hline CR & $6,05 \mathrm{E}-07^{* *}$ & $9,10 \mathrm{E}-07^{* * *}$ & $6,38 \mathrm{E}-07^{* *}$ & $0,0000^{*}$ & $6,57 \mathrm{E}-07^{* *}$ \\
\hline FLO & $0,3180^{* *}$ & $0,3291^{* * *}$ & $0,3210^{* *}$ & $0,3176^{* *}$ & $0,3082^{* * *}$ \\
\hline OUTLIER & $197,7095^{* * *}$ & $173,1386^{* * *}$ & $200,7926^{* * *}$ & $162,2973^{* *}$ & $159,1636^{* * *}$ \\
\hline D2002 & $-32,0931^{* * *}$ & $-33,8581^{* * *}$ & $-37,5683^{* * *}$ & $-25,9950^{* * *}$ & $-39,9115^{* * *}$ \\
\hline D2003 & $-22,9873^{* * *}$ & $-25,6477^{* * *}$ & $-30,6820^{* * *}$ & $-20,6097^{* * *}$ & $-31,1214^{* * *}$ \\
\hline D2004 & $-20,5102^{* *}$ & $-23,4773^{* * *}$ & $-31,0413^{* * *}$ & $-20,6342^{* * *}$ & $-32,9350^{* * *}$ \\
\hline D2005 & $-19,7990^{*}$ & $-25,2962^{* * *}$ & $-31,6717^{* *}$ & $-21,1991^{* * *}$ & $-30,5555^{* * *}$ \\
\hline D2006 & $-5,2938$ & $-8,3381$ & $-16,6478$ & $-10,6734$ & $-14,8675$ \\
\hline WY & - & - & $0,0098^{* * *}$ & $0,0086^{* *}$ & $0,0091^{* * *}$ \\
\hline WY2 & - & - & $-4,04 \mathrm{E}-07^{* * *}$ & $-3,54 \mathrm{E}-07^{* *}$ & $-3,17 \mathrm{E}-07^{* * *}$ \\
\hline WY3 & - & - & $3,49 \mathrm{E}-12^{* * *}$ & $3,07 \mathrm{E}-12^{* *}$ & $2,72 \mathrm{E}-12^{* * *}$ \\
\hline WBOV & - & - & $0,0002^{* * *}$ & $-0,0001$ & $0,0004^{* * *}$ \\
\hline WSOJA & - & - & $0,0010^{* * *}$ & 0,0005 & $0,0004^{* *}$ \\
\hline WCANA & - & - & $-0,0112$ & $-0,0082$ & $-0,0147^{* * *}$ \\
\hline WEXTM & - & - & 0,0000 & 0,0000 & 0,0000 \\
\hline WEXTNM & - & - & $-0,0060^{* *}$ & $-0,0036$ & $-0,0045^{* *}$ \\
\hline WSILV & - & - & $-0,0001$ & $-3,13 \mathrm{E}-05$ & $-0,0001$ \\
\hline
\end{tabular}


Desmatamento e Crescimento Econômico no Brasil: uma análise da Curva de Kuznets Ambiental para a Amazônia Legal

\begin{tabular}{|c|c|c|c|c|c|}
\hline & Modelo (1) & Modelo (2) & Modelo (3) & Modelo (4) & Modelo (5) \\
\hline WDPOP & - & - & $-0,0099$ & 0,0166 & 0,0259 \\
\hline WCR & - & - & 3,64E-07 & 7,27E-08 & $6,22 \mathrm{E}-07^{* *}$ \\
\hline WFLO & - & - & 0,0060 & $-0,0791$ & 0,0274 \\
\hline $\begin{array}{l}\text { Número de } \\
\text { observações }\end{array}$ & 4692 & 4692 & 4692 & 4692 & 4692 \\
\hline AIC & 5078 & 4859 & 5161 & 4387 & 4701 \\
\hline $\begin{array}{l}\text { Autocorrela- } \\
\text { ção espacial } \\
\text { dos resíduos }\end{array}$ & $\begin{array}{l}\text { Presente em } \\
\text { todos os anos }\end{array}$ & $\begin{array}{l}\text { Presente } \\
\text { em } 2005\end{array}$ & $\begin{array}{l}\text { Presente em } \\
\text { todos os anos }\end{array}$ & $\begin{array}{c}\text { Presente em } \\
2002,2003 \\
2004,2006\end{array}$ & $\begin{array}{l}\text { Presente } \\
\text { em } 2006\end{array}$ \\
\hline \multicolumn{6}{|c|}{${ }^{*} p$-valor $<0,10 ;{ }^{* *} p$-valor $<0,05 ;{ }^{* * *} p$-valor $<0,01}$. \\
\hline \multicolumn{6}{|c|}{$\begin{array}{l}\text { OUTLIER representa uma variável dummy para os municípios considerados outliers superiores em área desmatad } \\
\text { anual, detectados na Aede. }\end{array}$} \\
\hline \multicolumn{6}{|c|}{$\begin{array}{l}\text { (1) Modelo de defasagem espacial; (2) modelo de erro espacial; (3) modelo regressivo cruzado espacial; (4) model } \\
\text { Durbin espacial; (5) modelo de erro espacial e transbordamentos espaciais. }\end{array}$} \\
\hline
\end{tabular}

Cabe ressaltar que para nenhum dos modelos a hipótese da EKC tradicional foi verificada: ao contrário, os resultados obtidos para o melhor modelo evidenciam uma relação entre desmatamento e crescimentoem formato de "N" invertido, em que a área desmatada decresce para baixos níveis de PIB per capita, torna-se crescente à medida que os níveis de renda se elevam, em seguida tornando-se decrescente para os níveis de renda mais elevados. ${ }^{7}$ Uma interpretação para este formato da relação poderia ser a seguinte:

1. A ocupação inicial causa o desmate da área, sem gerar renda neste primeiro momento;

2. A atividade ali instalada de maneira incipiente gera renda ainda pequena;

3. À medida que a renda se eleva, expande-se também a atividade, causando mais desmatamento;

4. Com níveis de renda mais elevados, dispõe-se de mais acesso a informação e educação, o que pode levar à uma maior produtividade da atividade desenvolvida no local e também ao conhecimento das questões ambientais, diminuindo a pressão sobre a floresta. Entretanto, como os pontos de inflexão relativos aos pontos de mínimo e máximo

7 A relação na forma de" $\mathrm{N}$ " invertido foi também encontrada por Ciriaci e Palma (2009), em um estudo sobre concentração de $\mathrm{CO}_{2}$ em regiões da Itália. 
locais ${ }^{8}$ situam-se, aproximadamente, entre zero e $\mathrm{R} \$ 78.000$ (um valor de PIB per capita municipal bem acima da média da região), há a indicação de que a grande parte dos municípios encontra-se na fase intermediária dessa relação (parte ascendente da curva) e ainda apresentará aumento do desmatamento com o crescimento econômico.

\section{Conclusão}

Este trabalho investigou a hipótese da Curva de Kuznets Ambiental (EKC) para a região da Amazônia Legal, isto é, se existe uma relação entre um indicador de degradação ambiental e crescimento econômico da região, na forma de " $U$ " invertido. $\mathrm{O}$ indicador de degradação ambiental mais relevante, neste caso, é o desmatamento, expresso pelo incremento anual da área desmatada (em $\mathrm{km}^{2}$ ), monitorado pelo Sistema Prodes (Inpe), para os municípios da região. O crescimento econômico foi expresso pelo PIB per capita municipal. O estudo abrange o período de 2001 a 2006.

O desmatamento é um processo de forte natureza espacial, uma vez que acontece principalmente nas vizinhanças de áreas desmatadas anteriormente. Para contemplar este aspecto, a consideração de efeitos espaciais nos estudos sobre desmatamento tem-se mostrado importante. Este trabalho contribuiu com uma análise econométrico-espacial, utilizando um painel de dados mais extenso que os de estudos anteriores. Além da EKC, outras variáveis explicativas, relatadas em literatura como condicionantes do processo de desmatamento, foram incluídas no modelo econométrico: rebanho bovino, áreas cultivadas de soja e cana-de-açúcar, extração de produtos madeireiros e não madeireiros, silvicultura de produtos madeireiros, densidade populacional, crédito rural e existência de floresta anterior.

A análise econométrica parte de um modelo global para o desmatamento na Amazônia, e a estimação por efeitos fixos mostra-se a mais apropriada. Este fato está de acordo com o esperado, pois muitos dos determinantes do desmatamento são características peculiares ao município e praticamente invariantes no

8 Os valores de PIB percapita de zero e R 77.262 para os pontos de mínimo e máximo locais, respectivamente, foram encontrados considerando-se que o coeficiente $\alpha_{2}$ da função cúbica (equação 2) é igual a zero, visto que, no modelo econométrico (5, Tabela 4), tal coeficiente apresenta-se não significativo. Caso o valor deste coeficiente $\alpha_{2}$ seja considerado não zero, os pontos de mínimo e máximo locais tornam-se, respectivamente, $R \$ 19.469$ e $R \$ 57.793$, fato que situa os municípios na fase anterior e na fase intermediária da curva, principalmente, indicando, da mesma maneira, uma perspectiva de aumento do desmatamento com o crescimento econômico. 
período de estudo, tais como potencial agropecuário do solo, pluviosidade, áreas protegidas e distância de mercados.

O modelo-base, entretanto, não indica a presença de uma relação do tipo da EKC em nenhuma de suas formas. Vários modelos espaciais foram estimados alternativamente, e o que melhor se ajusta aos dados (com base na maior remoção da autocorrelação espacial dos resíduos e menor valor de AIC) é o modelo de erro espacial com transbordamentos espaciais. Neste último, as variáveis relativas ao rebanho bovino, crédito rural e área de floresta preexistente afetam positivamente o desmatamento. A relação entre desmatamento e crescimento econômico é verificada na forma de "N" invertido, ou seja, o desmatamento é decrescente para baixos níveis de PIB per capita, para depois crescer à medida que o PIB per capita se eleva, e torna-se decrescente novamente para níveis mais elevados de PIB per capita. A presença da relação da relação na forma de "N" nos municípios vizinhos mostra-se significativa. Ainda quanto aos transbordamentos espaciais, o cultivo de soja e a pecuária em municípios vizinhos contribuem para o desmatamento em determinado município; e, ao contrário, a presença de atividades de cultivo de cana-de-açúcar e extração de produtos não madeireiros nos municípios vizinhos contribui para um menor desmatamento.

O fato de a relação entre desmatamento e crescimento econômico da região amazônica poder ser expressa por meio de uma relação na forma de " $\mathrm{N}$ " invertido indica que há uma perspectiva de redução do desmatamento em níveis mais altos de renda, após uma fase de crescimento econômico com degradação ambiental. Entretanto, a maior parte dos municípios encontra-se na fase ascendente dessa relação. Aumento de produtividade nas áreas desmatadas, fortalecimento institucional para a proteção da floresta e maior consciência ambiental por meio de educação e acesso à informação são fatores que podem levar ao efeito esperado de redução do desmatamento. Políticas públicas voltadas para estas questões têm a capacidade de reduzir a altura e a convexidade da relação, acelerando o processo de redução do desmatamento.

\section{Referências Bibliográficas}

AGUIAR, A.P.; CÂMARA, G.; ESCADA, M.I.S. Spatial statistical analysis of land-use determinants in the Brazilian Amazonia: Exploring intra-regional heterogeneity. EcologicalModelling, 209, 2007. p.169-188.

ALMEIDA, E. S. Econometria Espacial Aplicada. Curso de Mestrado em Economia Aplicada, Universidade Federal de Juiz de Fora, 2008. Mimeografado.

ÂNGELO, H.; PEREIRA DE SÁ, S.P. Deforestation in BrazilianAmazon, Ciência Florestal, Santa Maria, v. 17, no 3, jul-set, 2007. p. 217-227. 
ARAÚJO, C. et al. Property rights and deforestation in the Brazilian Amazon. Ecological Economics (2009), doi: 10.1016/j.ecolecon. 2008.12.015

BARBIER, E.B.; BURGESS, J.C.The Economics of Tropical Deforestation.Journal of Economic Surveys, v.5, no3, 2002.

BATTHARAI, M.; HAMMIG, M. Institutions and Environmental Kuznets Curve for Deforestation: a Crosscountry analysis for Latin America, Africa and Asia. World Development, v.29, no, 2001.

BAUM, C.F. An Introduction to Modern Econometrics Using Stata. Stata Press, 2006.

BAUMONT, C. Spatial effects in housing price models: do housing prices capitalize urban development policies in the agglomeration of Dijon (1999)?Mimeo.,Université de Bourgogne, 2004.

BELL, K.P; BOCKSTAEL, N.E. Applying The Generalized-Moments Estimation Approach To Spatial Problems Involving MicrolevelData.The Review of Economics and Statistics, v. 82, no1, 2000. p. 72-82.

BECKER, B.K. Geopolítica da Amazônia. Estudos Avançados, 19 (53), 2005.

BRASIL. Lei Complementar no 124, de 3 de janeiro de 2007. Texto digitalizado. Disponível em http://www2.camara.gov.br/internet/legislacao/legin.html/ visualizarNorma.html?ideNorma $=548988$. Acesso em fev. 2009.

. Presidência da República. Plano Amazônia Sustentável: diretrizes para o desenvolvimento sustentável da Amazônia Brasileira. Brasília, 2008. 112 p.

BROWN, J.C. et al. Soybean Production and Conversion of Tropical Forest in the Brazilian Amazon: The Case of Vilhena, Rondonia. Ambio Vol. 34, no6, 2005.

CALDAS, M.M. et al. Ciclo de Vida da Família e Desmatamento na Amazônia: Combinando Informações de Sensoriamento Remoto com Dados Primários. Revista Brasileira de Economia, 57(4): 683-711, Rio de Janeiro, 2003.

CARVALHO, T. S. A Hipótese da Curva de Kuznets Ambiental Global e o Protocolo de Quioto. 2008. 130 f. Dissertação (Mestrado em Economia Aplicada). Faculdade de Economia e Administração, Universidade Federal de Juiz de Fora, 2008.

CHIMELI, A.B. Growth and the environment: Are we looking at the right data? Economics Letters, no96, 2007. p. 89-96.

CHOMITZ, K.M.; THOMAS, T.S., Determinans of Land Use in Amazônia: A fine-scale Spatial Analysis. American Journal of Agricultural Economics. 85(4), 2003. p. 1016-1028. 
Desmatamento e Crescimento Econômico no Brasil:

uma análise da Curva de Kuznets Ambiental para a Amazônia Legal

CIRIACI, D., PALMA, D. Geography, enviromental efficiency and economic growth: how to uncover localized externalities through spatial econometric modeling. SEA, III World Conference.Barcelona, 2009.

CULAS, R.J. Deforestation and the environmental Kuznets curve: An institutional perspective. Ecological Economics, v.61, 2007. p. 429-437.

DE BRUYN, S. M.; VAN DEN BERGH, J. C. J. M.; OPSCHOOR, J. B. Economic Growth and Emissions: reconsidering the empirical basis of environmental Kuznets curves. Ecological Economics, vol. 25, 1998. p. 161-175.

ELHORST, J.P. Specification and estimation of spatial panel data models. International Regional Science Review, vol. 26, no3, 2003. p. 224-268.

EWERS, R.M.; LAURANCE, W.F.; SOUZA JR, C.M. Temporal fluctuations in Amazonian deforestation rates. Environmental Conservation, v.35, № 4, 2008. p. 303-310.

FERREIRA, A.M.M.; SALATI, E. Forças de transformação do ecossistema amazônico. Estudos Avançados, 19 (54), 2005.

FERREIRA, L.V.; VENTICINQUE, E.; ALMEIDA, S.O desmatamento na Amazônia e a importância das áreas protegidas. Estudos avançados, v.19, nํ53, 2005.

GOMES, S.C.; BRAGA, M.J. Desenvolvimento Econômico e Desmatamento na Amazônia Legal: uma análise econométrica. Trabalho apresentado no XLVI Congresso da Sociedade Brasileira de Economia, Administração e Sociologia Rural (SOBER), 2008.

IGLIORI, D.C. Deforestation, Growth and Agglomeration Effects: Evidence from Agriculture in the Brazilian Amazon. XXXIV Encontro Nacional de Economia. ANPEC, 2006.

INPE - INSTITUTO NACIONAL DE PESQUISAS ESPACIAIS. Relatório Monitoramento da Cobertura florestal da Amazônia por Satélites. Sistemas PRODES, DETER, DEGRAD E QUEIMADAS 2007-2008. INPE, Ministério da Ciência e Tecnologia, 2008.

. CRA/INPE mapeia vegetação secundária do Pará, Mato Grosso e Amapá. Disponível em http://www.inpe.br/noticias/noticia.php?Cod_Noticia=1934. Acesso em set. 2009.

KAIMOWITZ, D.; ANGELSEN, A. Economic Models of Tropical Deforestation: a Review. CIFOR, Jacarta, 1998.

KELEJIAN, H.; PRUCHA, I. A generalized spatial two stage least squares procedure for estimating a spatial autoregressive model with autoregressive disturbances. Journal of Real Estate Finance and Economics, no 17, p. 99-121, 1998. 
LEE, L.-f.GMM and 2SLS estimation of mixed regressive, spatial autoregressive models. JournalofEconometrics, 137, 2007. p.489-514.

MARGULIS, S. Causas do desmatamento da Amazônia brasileira. Banco Mundial, 2003.

MINISTÉRIO DO MEIO AMBIENTE. Projeto Macrozoneamento Econômicoecológico da Amazônia Legal: Marco Teórico-Conceitual. Disponível em http:// www.mma.gov.br. Acesso em julho/2009.

MIRAGAYA, J. Demanda mundial de carne bovina tem provocado o desmatamento na Amazônia. TEC Amazônia, anoVI, nº 14, 2008.

OLIVEIRA, R.C. Desmatamento na Amazônia Legal: uma análise econométricaespacial para a Curva de Kuznets Ambiental. Trabalho apresentado às disciplinas Econometria Espacial e Métodos Quantitativos III, Mestrado em Economia Aplicada, Universidade Federal de Juiz de Fora, 2009.

PFAFF, A.S.P. What Drives Deforestation in the Brazilian Amazon? Journal of Environmental Economics and Management, v.37, 1999. p.26-43.

PINDYCK, R.S.; RUBINFELD, D.L. Econometria: Modelos\&Previsões. Editora Campus, 2004.

PRATES, R.C. O desmatamento desigual na Amazônia brasileira: sua evolução, suas causas e conseqüências para o bem-estar. 2008. 160f. Tese (Doutorado em Economia Aplicada). Escola Superior de Agricultura Luiz de Queiroz, Universidade de São Paulo, 2008.

REIS, E. J.; GUZMAN, R. M.. Um modelo econométrico do desflorestamento da Amazônia. Pesquisa e Planejamento Econômico, v. 23, no 1, 1993. p.33-64.

SANTOS, R.B.N et al. Estimativa da Curva de Kuznets Ambiental para a Amazônia Legal. Trabalho apresentado no XLVI Congresso da Sociedade Brasileira de Economia, Administração e Sociologia Rural (SOBER), 2008.

SILVA, A.N. Análise das relações entre o desflorestamento e o potencial agropecuário das terras na Amazônia. 2006. 179 f. Dissertação (Mestrado em Sensoriamento Remoto), Instituto Nacional de Pesquisas Espaciais, 2006.

SUPERINTENDÊNCIA DE DESENVOLVIMENTO DA AMAZÔNIA (SUDAM). Disponível em http://www.ada.gov.br/index.php?option=com_content\&task= view\&id=40\&Itemid $=49$. Acesso em 25 mar. 2009.

STERN, D.I. The Rise and Fall of the Environmental Kuznets Curve. World Development, Vol. 32, no8, 2004.p. 1419-1439.

TRANCOSO, R. et al. Sistemas de Informação Geográfica como ferramenta para o diagnóstico e gestão de macrobacias no arco do desmatamento da Amazônia. 
Desmatamento e Crescimento Econômico no Brasil: uma análise da Curva de Kuznets Ambiental para a Amazônia Legal

In: Anais XII Simpósio Brasileiro de Sensoriamento Remoto. Goiânia, Brasil. INPE, 2005. p. 2405-2412.

VERA-DIAZ, M.C. et al. An interdisciplinary model of soybean yield in the Amazon Basin: The climatic, edaphic, and economic determinants. Ecological Economics, v.65, 2008. p. 420-431.

VITEL, C.S.M.N.; FEARNSIDE, P.M.; GRAÇA, P.M.L.A. Análise da inibição do desmatamento pelas áreas protegidas na parte sudoeste do Arco do Desmatamento. In: Anais XIV Simpósio Brasileiro de Sensoriamento Remoto. Natal, Brasil. INPE, 2009. p. 6377-6384.

WOOLDRIDGE, J.M. Econometric analysis of cross section and panel data.Boston, Massachusetts: MIT, 2002. 
Rejane Corrêa de Oliveira, Eduardo Almeida, Ricardo da Silva Freguglia e 739 Ricardo Candéa Sá Barreto

\begin{tabular}{|c|c|c|c|c|c|c|c|c|c|c|c|c|c|}
\hline$\stackrel{0}{\circ}$ & & & & & & & & & & & & & \& \\
\hline $\begin{array}{l}\hat{0} \\
\hat{\bar{\theta}}\end{array}$ & & & & & & & & & & & & $\underset{8}{8}$ & $\begin{array}{l}\text { త్ర } \\
\stackrel{2}{0} \\
0 \\
0\end{array}$ \\
\hline$\widetilde{u}$ & & & & & & & & & & & $\underset{8}{8}$ & $\begin{array}{l}\text { N̂̀ } \\
\text { ล̀ } \\
\text { ò }\end{array}$ & $\begin{array}{l}\text { న̂ } \\
\text { ลે } \\
0 \\
0\end{array}$ \\
\hline 尝是是 & & & & & & & & & & $\underset{-}{\stackrel{8}{8}}$ & $\begin{array}{l}\sqrt{n} \\
\stackrel{5}{0} \\
0 \\
0\end{array}$ & $\begin{array}{l}\text { Tै } \\
8 \\
8 \\
0\end{array}$ & $\begin{array}{l}+1 \\
\text { 苜 } \\
\stackrel{0}{\circ}\end{array}$ \\
\hline 空量 & & & & & & & & & $\begin{array}{l}8 \\
8 \\
8 \\
-i\end{array}$ & $\mid \begin{array}{l}1 \\
0 \\
0 \\
0 \\
0 \\
1\end{array}$ & 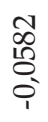 & 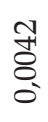 & $\begin{array}{l}10 \\
10 \\
0 \\
0 \\
0\end{array}$ \\
\hline 或界 & & & & & & & & $\underset{8}{8}$ & $\begin{array}{l}2 \\
2 \\
10 \\
0 \\
0\end{array}$ & $\mid \begin{array}{l}2 \\
g \\
0 \\
\vdots \\
0\end{array}$ & 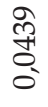 & $\begin{array}{l}\infty \\
\infty \\
\stackrel{0}{0} \\
0 \\
0\end{array}$ & 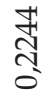 \\
\hline$\underset{ن}{Z}$ & & & & & & & $\underset{\substack{8 \\
8}}{8}$ & $\begin{array}{l}\text { oे } \\
\text { o. } \\
\text { i }\end{array}$ & 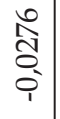 & $\mid \begin{array}{c}1 \\
0 \\
0 \\
0 \\
0 \\
1 \\
1\end{array}$ & $\begin{array}{l}0 \\
\text { ND } \\
\text { [n } \\
\text { - }\end{array}$ & $\begin{array}{l}\overrightarrow{6} \\
0 \\
0 \\
0 \\
0\end{array}$ & 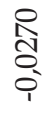 \\
\hline 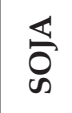 & & & & & & $\underset{8}{8}$ & 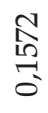 & $\begin{array}{l}+ \\
0 \\
0 \\
0 \\
0\end{array}$ & 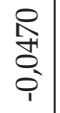 & 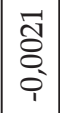 & $\begin{array}{l}\infty \\
\stackrel{\infty}{\circ} \\
\infty \\
0 \\
0\end{array}$ & 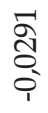 & 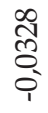 \\
\hline o & & & & & $\underset{-}{8}$ & $\begin{array}{l}\stackrel{0}{7} \\
\stackrel{2}{0} \\
0\end{array}$ & 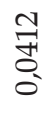 & $\stackrel{5}{\sigma}$ & $\begin{array}{l}10 \\
0 \\
0 \\
0 \\
0 \\
1\end{array}$ & $\begin{array}{l}0 \\
0 \\
8 \\
0 \\
0\end{array}$ & 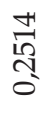 & \begin{tabular}{l}
1 \\
\multirow{2}{0}{} \\
0 \\
0 \\
0 \\
0
\end{tabular} & 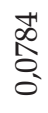 \\
\hline$\stackrel{\infty}{二}$ & & & & $\underset{-}{8}$ & 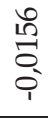 & 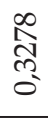 & $\begin{array}{l}\text { 茴 } \\
8 \\
8 \\
0\end{array}$ & $\begin{array}{l}\stackrel{m}{m} \\
\stackrel{2}{0} \\
\stackrel{0}{1}\end{array}$ & $\begin{array}{l}\vec{b} \\
0 \\
0 \\
0 \\
0\end{array}$ & 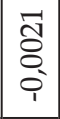 & 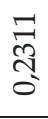 & 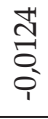 & 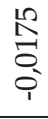 \\
\hline 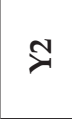 & & & $\underset{-}{8}$ & $\begin{array}{l}\text { స్ } \\
\text { જू }\end{array}$ & 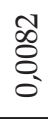 & $\begin{array}{l}\text { लิ } \\
\text { in } \\
\text { \& }\end{array}$ & 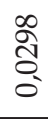 & $\begin{array}{l}\stackrel{\infty}{+} \\
\stackrel{+}{0} \\
\stackrel{1}{1}\end{array}$ & $\begin{array}{l}\tau \\
0 \\
0 \\
0 \\
0\end{array}$ & $\begin{array}{l}\text { ণิ } \\
\text { ठ } \\
\text { ○ }\end{array}$ & 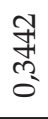 & 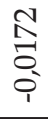 & 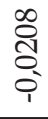 \\
\hline$\succ$ & & $\underset{-}{8}$ & $\begin{array}{l}10 \\
\infty \\
1 \\
\infty \\
0 \\
0\end{array}$ & $\begin{array}{l}\stackrel{\circ}{0} \\
\stackrel{+}{\hat{1}} \\
\text { ó }\end{array}$ & $\begin{array}{l}\text { 今ิ } \\
\text { in } \\
\text { - }\end{array}$ & $\begin{array}{l}+1 \\
0 \\
0 \\
0 \\
0\end{array}$ & 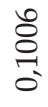 & 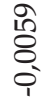 & $\begin{array}{l}0 \\
0 \\
0 \\
0 \\
0 \\
1\end{array}$ & $\begin{array}{l}\stackrel{0}{~} \\
\text { ป̂ } \\
0 \\
0\end{array}$ & 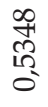 & 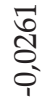 & 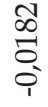 \\
\hline$\sum_{\substack{n \\
0}}$ & $\underset{8}{8}$ & 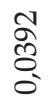 & 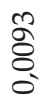 & $\begin{array}{l}1 \\
\text { \&̊ } \\
\text { o }\end{array}$ & $\begin{array}{l}\text { న̂న } \\
\stackrel{1}{1} \\
\stackrel{2}{0}\end{array}$ & $\begin{array}{l}0 \\
\stackrel{7}{*} \\
\stackrel{0}{0}\end{array}$ & 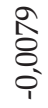 & 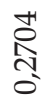 & $\begin{array}{l}0 \\
0 \\
8 \\
0 \\
1\end{array}$ & 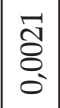 & $\begin{array}{l}\text { m } \\
\text { g̊ } \\
0 \\
0\end{array}$ & $\begin{array}{l}\frac{\partial}{2} \\
8 \\
0 \\
0\end{array}$ & 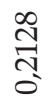 \\
\hline & $\sum_{\substack{n \\
1 \\
0}}$ & $\succ$ & 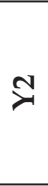 & $\stackrel{\infty}{2}$ & ○े & $\frac{\varsigma}{\circ}$ & 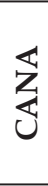 & 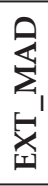 & 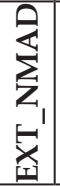 & 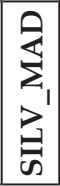 & 艺 & $\begin{array}{l}\hat{0} \\
\hat{0}\end{array}$ & $\stackrel{0}{0}$ \\
\hline
\end{tabular}


